\section{WHO SEEK HOMEOPATHIC TREATMENT?}

Sheikh Faruque Elahee', Md. Mizanur Rahman², Md. Mahfuzar Rahman $^{3}$, Shaila Hossain ${ }^{4}$, Mahbub Zaki ${ }^{5}$

\begin{abstract}
:
Homeopathy, or homeopathic medicine, is a holistic system of treatment and is based on the idea that substances that produce symptoms of sickness in healthy people will have a curative effect when given in very dilute quantities to sick people who exhibit those same symptoms. Homeopathic physicians seek to cure their patients on the physical, mental and emotional levels, and each treatment is tailored to a patient's individual needs. Considering these ideas a cross sectional study was conducted in Dhaka city from March to July, 2008 to determine the characteristics of patients seeking homeopathic treatment. A sample of 250 patients was selected for interview for the study. About one third (31\%) of the patients prefer homeopathic treatment and the rest also take other treatments like Allopathic, Ayurbedic and Unani. Majority of the patients chose homeopathic treatment as it has long lasting cure (54\%), low cost (27\%) and no side effect (25\%). The common diseases for which homeopathic treatment was sought were skin diseases (16\%), gastrointestinal diseases (15\%), genital diseases (14\%), ENT diseases (13\%) and musculo-skeletal diseases (12\%). About 76\% patients had previous experience of homeopathic treatment, while $24 \%$ received it for the first time. Bi-variate analysis revealed that young age, unmarried and higher income groups of patients were found to be more regular in receiving homeopathic treatment than the older, married and low income groups $(\mathrm{p}<0.05)$. Though the study finding did not generalize the medicare system of Bangladesh, but it need to be integrated into the conventional medicine to achieve health for all.
\end{abstract}

Keywords: Homeopathic treatment, characteristics of patients, family income, common diseases, Bangladesh.

\section{Introduction:}

In Bangladesh, $51 \%$ of the population is devoid of any health care service. Of the remaining $49 \%$, only $20 \%$ uses conventional (allopathic) medical treatment and the rest (29\%) uses homeopathic and other alternative medicines. ${ }^{1}$ It is obvious that in order to achieve Health for All, alternative medicines must be incorporated in the health care of the people along with conventional medicine, which is also suggested by the World Health Organization.

Homeopathy is a popular system of alternative medicines throughout the world as well as in Bangladesh. Though European in origin, it became very popular in the Indian subcontinent right from the time

1. Member, Bangladesh Homeopathic Board, Dhaka, Bangladesh

2. Associate Professor and Head, Department of Biostatistics, National Institute of Preventive and Social Medicine (NIPSOM), Mohakhali, Dhaka-1212

3. Professor and Head, Department of Community Medicine, NIPSOM.

4. Associate Professor, Department of Community Medicine, NIPSOM.

5. Consultant, Faculty of Dentistry, Bangabandhu Sheikh Mujib Medical University, Dhaka-1000. of Hahnemann, the founder of Homeopathy. After independence of Bangladesh, all governments paid due attention in the development of homeopathy by setting up a Government. Homeopathic Medical College with 100 bedded hospital, a Directorate of Homeopathy and Indigenous Medicines. The University of Dhaka recognized the system by conferring a 5-year course of Bachelor of Homeopathic Medicine and Surgery (BHMS). Besides there are 37 homeopathic Diploma colleges overseen by the Bangladesh Homeopathy Board. There are tens of thousands of homeopathic practitioners practicing in the country. Previously it was the poor section of the population where homeopathy was popular, as it is a low-cost medicine; but now patients from affluent society also consult homeopathic practitioners for treatment. $^{2}$

In western countries ${ }^{2-14}$, Israel ${ }^{15}$, India ${ }^{16}$ and Pakistan ${ }^{17}$ many epidemiological studies have been undertaken to explore the socio-demographic characteristics of the patients seeking homeopathic treatment, range of diseases treated by homeopaths, even there are many comparative studies between effectiveness of homeopathic treatment with conventional treatment. In Bangladesh, no such epidemiological study is yet available and the present study may stimulate others to conduct such studies which may help in the planning of health care of the people.

\section{Materials and Methods:}

The study was designed with the major objective to determine the characteristics of patients seeking homeopathic treatment. The study was conducted in Dhaka city, where the patients attending private chambers of homeopathic practitioners were taken as the study population. A sample of 250 patients was selected purposively for interview using a semi-structured interview schedule and was interviewed at their exit point. The respondents were informed about the purpose of the study and their voluntary participation was sought. Before interviewing, a written informed consent was taken assuring that the collected data would be kept confidential. Data were collected, checked and cross-checked (triangulation) before entry into a computer and analyzed with the help of SPSS Windows Software Programme (version 16).

\section{Results:}

The mean age of the patients was $38.3 \pm 14$.3 years, the highest percentage (30\%) being in the age group 25-34 years. More than half of the (56.4\%) patients were male and the rest were female (43.6\%). Most of the patients were Muslim (95.4\%) and only 3.6\% were Hindus. Majority were married (74.4\%); (18.8\%) were unmarried. The highest percentage of patients was housewives (30.4\%), followed by private service $(20.8 \%)$, business (11.6\%), govt. service (9.2\%), labourer (9.2\%) etc. The median monthly family income was Taka 10,000, ranging from Tk. 1300 to 100,000. The mean family size was $5.3 \pm 2$ ranging from 1 to 15 (Table-I). About 31\% patients were taking only homeopathic treatment whereas $69 \%$ patients sometimes take other treatment also like Allopathic, Ayurvedic and Unani (Table-II). Regarding reasons for seeking homeopathic treatment, 
Table-I: Socio-demographic characteristics of the patients $(n=250)$

\begin{tabular}{|c|c|c|c|}
\hline Characteristics & Frequency & Percent & Statistics \\
\hline \multicolumn{4}{|l|}{ Age in years } \\
\hline$<25$ & 36 & 14.4 & $38.3 \pm 14.3$ years \\
\hline $25-34$ & 75 & 30.0 & \multirow[t]{4}{*}{ Range $=12-90$ years } \\
\hline $35-44$ & 70 & 28.0 & \\
\hline $45-54$ & 39 & 15.6 & \\
\hline$\geq 55$ & 30 & 12.0 & \\
\hline \multicolumn{4}{|l|}{ Sex } \\
\hline Male & 141 & 56.4 & \\
\hline Female & 109 & 43.6 & \\
\hline \multicolumn{4}{|l|}{ Religion } \\
\hline Islam & 241 & 96.4 & \\
\hline Hinduism & 9 & 3.6 & \\
\hline \multicolumn{4}{|l|}{ Marital status } \\
\hline Married & 186 & 74.4 & \\
\hline Unmarried & 47 & 18.8 & \\
\hline Widow & 14 & 5.6 & \\
\hline Widower & 3 & 1.2 & \\
\hline \multicolumn{4}{|l|}{ Occupation } \\
\hline Housewife & 76 & 30.4 & \\
\hline Private service & 52 & 20.8 & \\
\hline Business & 29 & 11.6 & \\
\hline Govt. service & 23 & 9.2 & \\
\hline Labourer & 23 & 9.2 & \\
\hline Student & 20 & 8.0 & \\
\hline Retired & 12 & 4.8 & \\
\hline Farmer & 8 & 3.2 & \\
\hline Others & 7 & 2.8 & \\
\hline \multicolumn{4}{|c|}{ Monthly family income (Tk.) } \\
\hline Up to 5000 & 66 & 26.4 & Median income $=$ \\
\hline 5001-10000 & 76 & 30.4 & Tk. 10000.00; \\
\hline $10001-15000$ & 33 & 13.2 & Range $=$ Tk. 1300 \\
\hline $15001-20000$ & 20 & 8.0 & to 100000 \\
\hline$\geq 20001$ & 55 & 22.0 & \\
\hline \multicolumn{4}{|l|}{ Family size } \\
\hline $1-2$ & 12 & 4.8 & Mean $\pm \mathrm{SD}=$ \\
\hline $3-4$ & 81 & 32.4 & $5.3 \pm 2.0$; Range $=$ \\
\hline $5-6$ & 105 & 42.0 & 1 to 15 \\
\hline $7-8$ & 36 & 14.4 & \\
\hline$\geq 9$ & 16 & 6.4 & \\
\hline
\end{tabular}

the patients said that it has long lasting cure (54\%), low cost (26.8\%), no side effect (25.2\%), no need for pathological tests (16.8\%), not cured by allopathic treatment (9.2\%) etc (Table-III). The range of diseases for which treatment was sought were skin diseases (16.4\%), gastrointestinal diseases (14.8\%), genital diseases (13.6\%), ENT diseases (12.8\%), musculoskeletal diseases $(12 \%)$, respiratory diseases $(7.6 \%)$, urinary diseases (4.8\%), hepatobilliary diseases (3.2\%) etc (Table-IV).
Table-II: Pattern of care seeking behaviour

\begin{tabular}{lcc}
\hline Characteristics & Frequency & Percent \\
\hline Regular homeopathic treatment(n=250) & 78 & 31.2 \\
Yes & 172 & 68.8 \\
No & & \\
Other sources of treatment $(\mathrm{n}=172)$ & 169 & 98.3 \\
Allopathic & 33 & 19.2 \\
Ayurvedic & 16 & 9.3 \\
Unani & 4 & 2.3 \\
Traditional & & \\
\hline
\end{tabular}

Table-III: Reasons for taking homeopathic treatment $(n=250)$

\begin{tabular}{lcc}
\hline Reasons for taking homeopathic treatment & Frequency & Percent \\
\hline Long lasting cure & 135 & 54.0 \\
Low cost & 67 & 26.8 \\
No side effects & 63 & 25.2 \\
Unique treatment & 56 & 22.4 \\
No need for pathological test & 42 & 16.8 \\
Not cured by allopathic treatment & 23 & 9.2 \\
No need to be operated & 22 & 8.8 \\
Easy administration & 15 & 6.0 \\
By the advice of a relative & 11 & 4.4 \\
Knowing no hope in allopathic treatment & 7 & 2.8 \\
Witnessing the success of homeopathic treatment & 2 & 0.8 \\
By the advice of friends & 1 & 0.4 \\
\hline
\end{tabular}

*Multiple responses

Table-IV: Pattern of complaints seeking homeopathic treatment $(n=250)$

\begin{tabular}{lcc}
\hline Presenting complaints & Frequency & Percent \\
\hline Skin disease & 41 & 16.4 \\
GI disease & 37 & 14.8 \\
Complaints of genitalia & 34 & 13.6 \\
ENT disease & 32 & 12.8 \\
Musculoskeletal disease & 30 & 12.0 \\
Respiratory disease & 19 & 7.6 \\
Urinary tract disease & 12 & 4.8 \\
Hepatobilliary disease & 8 & 3.2 \\
Eye disease & 5 & 2.0 \\
Neurological disease & 5 & 2.0 \\
Mental disease & 4 & 1.6 \\
Cardiovascular disease & 2 & 0.8 \\
Glandular disease & 2 & 0.8 \\
Others & 19 & 7.6 \\
\hline
\end{tabular}

Data were analyzed to find any association between regularity of taking homeopathic treatment and sex, religion, marital status, level of education and monthly family income. Analysis revealed that younger age, unmarried and higher income groups of patients were found to be more regular in taking homeopathic treatment than the older, married and lower income groups and the mean difference in each instance was statistically significant $(\mathrm{p}<0.05)($ Table-V). 
Table-V: Relationship between regularity of homeopathic treatment and selected socio-demographic characteristics

\begin{tabular}{|c|c|c|c|c|c|}
\hline \multirow[t]{3}{*}{ Variables } & \multicolumn{4}{|c|}{ Regularity of homeopathic treatment } & \multirow[t]{3}{*}{$\mathrm{p}$ value } \\
\hline & \multicolumn{2}{|c|}{ Yes $(n=78)$} & \multicolumn{2}{|c|}{ No $(n=172)$} & \\
\hline & No. & $\%$ & No. & $\%$ & \\
\hline \multicolumn{6}{|l|}{ Age in years } \\
\hline$<25$ & 18 & 50.0 & 18 & 50.0 & \\
\hline $25-34$ & 22 & 29.3 & 53 & 70.7 & \\
\hline $35-44$ & 23 & 32.9 & 47 & 67.1 & \\
\hline $45-54$ & 8 & 20.5 & 31 & 79.5 & \\
\hline e”55 & 7 & 23.3 & 23 & 76.7 & \\
\hline$\S$ Mean \pm SD (yrs) & $35.4 \pm 13.4$ & $39.6 \pm 14.6$ & $\mathrm{p}<0.005$ & & \\
\hline \multicolumn{6}{|l|}{ Sex } \\
\hline Male & 42 & 29.8 & 99 & 70.2 & $\mathrm{p}>0.05$ \\
\hline Female & 36 & 33.0 & 73 & 67.0 & \\
\hline \multicolumn{6}{|l|}{ Religion } \\
\hline Islam & 75 & 31.1 & 166 & 68.9 & $\mathrm{p}>0.05$ \\
\hline Hinduism & 3 & 33.3 & 6 & 66.7 & \\
\hline \multicolumn{6}{|l|}{ Marital status } \\
\hline Married & 57 & 28.1 & 146 & 71.9 & $\mathrm{p}<0.05$ \\
\hline Unmarried & 21 & 44.7 & 26 & 55.3 & \\
\hline \multicolumn{6}{|l|}{ Level of education } \\
\hline Illiterate & 6 & 21.4 & 22 & 78.6 & $\mathrm{p}>0.05$ \\
\hline Primary & 10 & 22.7 & 34 & 77.3 & \\
\hline Secondary & 22 & 34.4 & 42 & 65.6 & \\
\hline Higher secondary & 11 & 35.5 & 20 & 64.5 & \\
\hline Graduate & 16 & 42.1 & 22 & 57.9 & \\
\hline Masters & 10 & 29.4 & 24 & 70.6 & \\
\hline Madrasha & 3 & 30.0 & 7 & 70.0 & \\
\hline Diploma Engineer & 0 & 0.0 & 1 & 100.0 & \\
\hline \multicolumn{6}{|c|}{ Monthly family income (Tk.) } \\
\hline Up to 5000 & 18 & 27.3 & 48 & 72.7 & \\
\hline $5001-10000$ & 22 & 28.9 & 54 & 71.1 & \\
\hline 10001-15000 & 10 & 30.3 & 23 & 69.7 & \\
\hline 15001-20000 & 7 & 35.0 & 13 & 65.0 & \\
\hline e”20001 & 21 & 38.2 & 34 & 61.8 & \\
\hline$\S$ Mean \pm SD (Tk.) & $22344.87 \pm 27443.9$ & $14648.84 \pm 15964.1$ & $\mathrm{p}<0.05$ & & \\
\hline
\end{tabular}

$\S \mathrm{p}$ value reached from unpaired student’s t test and others were reached from Chi square test

\section{Discussion:}

The age pattern of the patients was similar to many Western, Israeli and Pakistani studies $2,5,7,14,15,17$ but differ with other Western studies $2,5,7$ where the patients were either older $3,4,6$ or younger ${ }^{8,9,11}$. Male patients (56\%) were found more than the female (44\%) and this finding was consistent with some European studies ${ }^{2-4,}$ 6-9, 12, 14 where there were obvious female predominance in the patients attending homeopathic medical practice. This might be fact that in European countries females have the liberty to choose their own doctors and they are often prone to seek attractive alternative medicines. Majority of the patients were married (74\%). This corresponds with the studies of Harrison et al., ${ }^{12}$ and Qidwai ${ }^{17}$. The highest percentage of the patients by occupation was housewives. It may be due to the fact that housewives find homeopathic practitioners easily accessible and who spare more time to listen to their myriads of womanly complaints patiently. It differs from many western ${ }^{5,12}$ and Pakistani ${ }^{17}$ studies where patients from other occupations predominated. The study revealed that about two thirds of patients sometimes use other treatment like Allopathic, Ayurvedic, Unani etc besides homeopathy, which conforms to other studies ${ }^{14,15,17}$ where patients were often found not to stick to one method of treatment for long. 
Regarding reasons for choosing homeopathic treatment, patients mentioned long lasting cure, low cost, no side effect, and no need for pathological tests, which reveal mostly the economic concern of the patients. Alton et al., ${ }^{13} 47 \%$ patients mentioned ineffectiveness of allopathic medicine, lack of side effects as the reason for choosing homeopathy. Studies showed that patients of different countries have different reasons for choosing homeopathic treatment. The range of common diseases for which homeopathic treatment was sought were found to be skin diseases, gastrointestinal diseases, genital diseases, ENT diseases, musculoskeletal diseases, respiratory diseases etc. The studies in $\mathrm{UK}^{3.4 .6 .13}$, France ${ }^{17}$, Norway ${ }^{8}$, Netherland $^{9}$, USA ${ }^{10,11}$, Germany ${ }^{14}$, Israel $^{15}$, India ${ }^{16}$ and Pakistan ${ }^{17}$ revealed the following diseases for which patients commonly consult a homeopath are ENT, psychiatric, dermatological, rheumatological, cardiovascular, respiratory, allergic, alimentary, gynecological diseases and even cancer. Again out of all these diseases three were found most common viz. psychiatric, dermatological and ENT diseases. Our study found that younger, unmarried and higher income groups of patients were found more regular in taking homeopathic treatment than the older, married and lower income groups.

This study was based only on patients seeking homeopathic treatment in Dhaka city. A nationwide survey should be done on patients seeking homeopathic as well as other alternative systems of medicine to know their socio-demographic characteristics, their views on the utility of different systems of medicines, ranges of diseases treated by different alternative medicines etc.

\section{References:}

1. Islam N. Situation Analysis and Utilization of Allopathic, Ayurbedic, Homeopathic and Unani Medicine in Bangladesh. Funded by WHO, 2003 (Unpublished).

2. Trichard M, Lamure E, Chaufferin G. Study of the practice of Homeopathic general practitioners in France. Homeopathy 2003; 92: 135-9.

3. Robinson T. Responses to Homeopathic treatment in National Health Service general practice. Homeopathy 2006; 95: 9-14.

4. Mathie RT, Robinson TW. Outcomes from Homeopathic prescribing in medical practice: A prospective, researchtargeted, pilot study. Homeopathy 2006; 95: 199-205.

5. Colin P. An epidemiological study of a Homeopathic practice. British Homeopathic Journal 2000; 89: 116-121.
6. Clover A. Patient benefit survey: Tunbridge Wells Homeopathic Hospital. British Homeopathic Journal 2000; 89: 68-72.

7. Slade K, Chohan BPS, Barker PJ. Evaluation of a GP practice based homeopathy service. Homeopathy 2004; 93: 67-70.

8. Steinsbekk A, Lüdtke R. Patients' assessments of the effectiveness of Homeopathic care in Norway: A prospective observational multi-centre outcome study. Homeopathy 2005; 94: 10-6.

9. Jansen GRHJ, Koster TGC. Complaints and diagnoses in Homeopathic practice. British Homeopathic Journal 1995; 84:140-3.

10. Jacobs J, Chapman EH, Crothers D. Patient characteristics and practice patterns of physicians using homeopathy. Arch Fam Med. 1998; 7: 537-40.

11. Jacobs J, Crothers D. Who sees Homeopaths? British Homeopathic Journal 1991; 80: 57-8.

12. Harrison C, Hewison J, Davies P, Pietroni P. The expectations, health beliefs and behaviour of patients seeking Homeopathic and conventional medicine. British Homeopathic Journal 1989;78:210-8.

13. Alton S, Kayne S. A pilot study of the attitudes and awareness of homeopathy shown by patients in three Manchester pharmacies. British Homeopathic Journal 1992; 81: 189-93.

14. Witt CM, Lüdtke R, Baur R. Homeopathic Medical Practice : Long-term results of a cohort study with 3981 patients. http://www.pubmedcentral.nih.gov/articlerender.fcgi? artid=1298309 (Viewed on 15.04.08).

15. Soffer T, Press Y, Peleg A. Characteristics of patients at a Complementary Medicine Clinic in Beer Sheva: Summary of the first two years of operation. http:// www.ncbi.nlm.nih.gov/pubmed/11519383 (Viewed on 20.04.08).

16. Manchanda RK, Kulhashreshtha M. Cost effectiveness and efficacy of homeopathy in primary health care units of the Government of Delhi - a study. http://www.thiemeconnect.com/ejournals/abstract/ahz/doi/10.1055/s-2005868641 (Viewed on 10.04.08).

17. Qidwai W. Utilization of services of Homeopathic Practitioners among patients in Karachi, Pakistan. http:// www.ayubmed.edu.pk/JAMC/PAST/15-3/waris.htm (Viewed on 17.04.08). 